\title{
Análise da hemoglobina como modelo de estudo de interação droga-proteína in vitro e in silico
}

Bianca Luiza Melo de Assis ${ }^{1}$ (D), Anderson Dillmann Groto ${ }^{1}$ (D), Vitor Hugo Sales da Mota $^{1}$ (D), Gabrielle Caroline Peiter ${ }^{2}$ (D), Kádima Nayara Teixeira ${ }^{1}$ (D)

\begin{abstract}
RESUMO
Modelo do estudo: Trata-se de um estudo experimental in vitro com abordagem computacional. Objetivo: Analisar a existência de interação entre as drogas hidrofóbicas bezafibrato e hidroclorotiazida com a hemoglobina a fim de prever alterações na biodisponibilidade das drogas, bem como na função proteica. Metodologia: Testes de interação in vitro entre a hemoglobina bovina e bezafibrato ou hidroclorotiazida foram realizados por espectrofotometria; análises dos sítios de interação e extrapolações para a hemoglobina humana foram feitas por técnicas de bioinformática. Resultados: Os testes in vitro demonstraram diminuição de absorbância (k) em $405 \mathrm{~nm}$ igual a $8,75 \times 10^{-4} \mathrm{~min}^{-1}$ para o bezafibrato e $6,25 \times 10^{-4} \mathrm{~min}^{-1}$ para a hidroclorotiazida. A diminuição sugere interação das drogas com a hemoglobina, sendo que o bezafibrato parece interagir com afinidade ligeiramente maior. As análises in silico mostraram que as drogas se ligam à porção proteica da hemoglobina. A constante de afinidade de ligação obtida por ancoragem molecular para o bezafibrato com a hemoglobina bovina $(-8,3 \mathrm{kcal} / \mathrm{mol}) \mathrm{corrobora} \mathrm{com} o$ valor experimental de $\mathrm{k}$ e com o maior número de interações observadas, em relação à hidroclorotiazida (-6,6 kcal/ $\mathrm{mol})$. O mesmo padrão é observado para a interação do bezafibrato $(-7,6 \mathrm{kcal} / \mathrm{mol})$ e da hidroclorotiazida $(-6,7$ $\mathrm{kcal} / \mathrm{mol}$ ) com a hemoglobina humana. Conclusão: As técnicas de espectrofotometria e bioinformática utilizadas sugerem a possibilidade de interação da hemoglobina com drogas de natureza hidrofóbica, como bezafibrato e hidroclorotiazida, sendo que essa interação pode afetar a função normal da hemoglobina e alterar a farmacodinâmica e farmacocinética das drogas prejudicando sua eficiência terapêutica.
\end{abstract}

Palavras-chave: Docagem Molecular; Hemoglobina; Interação Droga-proteína.

\section{INTRODUÇÃO}

Hemeproteínas, como a hemoglobina, têm sido usadas como modelo para estudar as interações droga-proteína para a compreensão da dinâmica da droga no organismo. Apesar de hemoglobinas estarem presentes nos eritrócitos, muitas drogas terapêuticas podem atravessar as barreiras da membrana e alcançá-las (CHAKRABORTI, 2003).

Sabe-se que a interação entre drogas e proteínas é responsável desde a ação desejada do suposto medicamento até os seus efeitos colaterais. Essas interações, em geral, podem influenciar a distribuição da droga no organismo, causar sua inativação, não permitindo uma concentração terapêutica de droga livre para ativar um receptor, ou mesmo retardar sua excreção (TONGA et al., 2011). Além disso, a ligação droga-proteína pode levar a mudanças tanto na estrutura secundária como terciária das proteínas (DUMAN, 2013); (WANG, 2009).
A associação de drogas com componentes do sangue é um processo reversível que geralmente envolve proteínas como albumina e a glicoproteína ácida a1. No entanto, componentes mais complexos como lipoproteínas, eritrócitos ou plaquetas podem estar envolvidos (KRATOCHOWIL et al., 2002; KWONG et al., 1985).

Proteínas como a albumina e a hemoglobina têm sido estudadas devido às interações com fármacos utilizados na prática clínica; é importante ter conhecimento sobre como essas interações podem afetar a função primordial dessas proteínas e como são afetadas a biodistribuição e os efeitos dos fármacos em tecidos-alvo (DUMAN, 2013).

A hemoglobina é uma importante hemeproteína associada ao transporte de oxigênio, sendo a principal proteína dos eritrócitos de vertebrados. Cada mililitro de sangue tem aproximadamente cinco bilhões de eritrócitos e cada eritrócito possui aproximadamente 280 milhões de moléculas de 
hemoglobina (WEST, 1985). A afinidade da hemoglobina pelo oxigênio é modulada por alguns ligantes, como prótons e 2,3-Bisfosfoglicerato (BPG), os quais reduzem a afinidade dessa proteína pelo oxigênio, por estabilizar seu estado T. Estes efeitos alostéricos são considerados naturais; entretanto, moléculas sintéticas têm sido examinadas devido ao seu potencial como moduladores alostéricos e possível aplicação terapêutica (LALEZARI et al., 1990).

Ao se utilizar a hemoglobina como modelo de estudo de interação droga-proteína, deve-se levar em consideração que as drogas podem se ligar a suas diferentes subunidades, em sua porção globina e/ou ao grupo heme, como ocorre com alguns antimaláricos (COSTA, 2007).

Diferentes distúrbios na hemoglobina ou mais especificamente no grupo heme podem alterar o funcionamento não só da hemoglobina como também de outras proteínas que possuem o grupo heme como grupo prostético, como os complexos proteicos do citocromo $\mathrm{P} 450$. Isto pode acarretar patologias específicas, por alterar a ligação e metabolização de drogas e fármacos, afetando assim os efeitos desejados no organismo.

Deste modo, fica clara a necessidade de determinar a existência de interações entre as diferentes drogas de uso clínico com proteínas do organismo e analisar a natureza dessas interações. Por se tratar de uma proteína plasmática, além de estar sendo extensivamente usada para pesquisas de interação proteína-ligante em estudos de toxicidade e segurança (LIU \& LIU, 2015; MALTAS \& OZMEN, 2015), neste trabalho sugere-se a utilização da hemoglobina como proteína modelo para estudo de interação droga-proteína, especificamente para drogas de caráter predominantemente hidrofóbico.

O bezafibrato é um fármaco hipolipemiante pertencente à classe dos fibratos e eficaz no tratamento da maioria das dislipidemias primárias e secundárias. Esta droga induz reduções acentuadas nos níveis de triglicérides e de lipoproteínas de baixa densidade ( $L D L$ ), bem como um aumento nos níveis de lipoproteínas de alta densidade (HDL). Esta ação do bezafibrato indica que ele pode ter um papel importante no retardo de processos ateroscleróticos e reduzir a morbidade cardiovascular (GOA et al., 1997).

A droga hidroclorotiazida é um diurético do grupo das benzotiazidas utilizada no tratamento de hipertensão arterial sistêmica, atuando no aumento da excreção renal de sódio e cloreto, a qual é acompanhada por volume correspondente de água (BRUNTON, 2019). Ambas as drogas são bastante conhecidas e amplamente utilizadas na terapêutica, e por apresentarem caráter hidrofóbico podem ser utilizadas como modelo para estudo de interação droga-proteína no escopo descrito.

A análise de interação entre moléculas atualmente tem sido muito facilitada por métodos computacionais, tais como, molecular docking ou ancoramento molecular que tem se mostrado útil e confiável para previsão das possíveis interações e de afinidade de ligantes com macromoléculas. Os métodos in silico vêm ganhando cada vez mais destaque, uma vez que a determinação experimental de estruturas tridimensionais complexas é bastante complexa e onerosa (HOBANI et al., 2017).

\section{MATERIAIS E MÉTODOS}

\section{Análise de interação droga-proteína in vitro}

Neste trabalho foi usada a forma holo da hemoglobina bovina purificada (Sigma ${ }^{\circledR}$ ) como uma proteína modelo. Para os experimentos de interação com as drogas, a hemoglobina foi solubilizada em PBS (Phosphate buffer saline) pH 7,4 no momento de uso na concentração de $6,7 \mathrm{mM}$.

Os fármacos de uso terapêutico em humanos que foram utilizados como modelo foram o bezafibrato (antilipêmico) e a hidroclorotiazida (anti-hipertensivo), ambos de natureza química primordialmente hidrofóbica. Os fármacos foram isolados a partir do medicamento comercial obtido em farmácia.

Ambos os fármacos, apresentados na forma de comprimido, foram macerados e solubilizados em PBS com o auxílio de um agitador magnético. Em seguida a mistura foi centrifugada a $5000 \mathrm{rpm}$ para separação e descarte dos excipientes. A presença do bezafibrato e da hidroclorotiazida foi detectada pela absorção em 230 nm e 273 nm, respectivamente.

Para as análises de interação, a hemoglobina bovina foi incubada com bezafibrato $0,01 \mathrm{~g} / \mathrm{mL}$ e com hidroclorotiazida $0,01 \mathrm{~g} / \mathrm{mL}$, isoladamente.

A interação droga-proteína in vitro foi avaliada pela análise da cinética de reação baseada na 
variação de absorbância em 405 nm (Banda Soret) por espectrofotometria, à temperatura ambiente $\left(25^{\circ} \mathrm{C}\right)$. As concentrações de proteína e droga foram ajustadas para simular as proporções fisiológicas e terapêuticas, respectivamente.

Como controle da reação, a hemoglobina bovina em PBS foi incubada nas mesmas condições experimentais, entretanto na ausência dos fármacos.

A variação da absorbância esperada trata-se de um decréscimo ( $k$ ), que foi calculado por meio da equação $k=\ln [$ (hemoglobina)t/(hemoglobina)0]. Os dados foram coletados a cada 2 min durante $40 \mathrm{~min}$. As reações de cinética foram realizadas em triplicada e submetidas à análise estatística pelo software Rstudio ${ }^{\circledR}$. Quando observada uma redução da absorção de luz durante a reação de cinética enzimática foi aplicado o teste de Wilcoxon-Mann-Whitney, comparando os resultados obtidos nos primeiros 10 min com os dados coletados entre os minutos 30 e 40, ajustados para a variação do controle.

\section{Análise de interação droga-proteína in silico}

As sequências primárias da hemoglobina bovina e da hemoglobina humana foram alinhadas pelo software ClustalX (THOMPSON et al., 1994). A ferramenta de alinhamento on-line da EMBL-EBI também foi utilizada para avaliar a similaridade das sequências estudadas (EMBL-EBI, 2020).

A hemoglobina bovina e a hemoglobina humana possuem estrutura tridimensional resolvida por cristalografia e difração de raios- $X$ depositadas no Protein Data Bank (PDB) (http://www.rcsb. org/pdb/home/home.do). Para as análises in silico foram utilizadas as estruturas 2QSS (Hb bovina) e $2 \mathrm{H} 35$ ( $\mathrm{Hb}$ humana). As estruturas químicas tridimensionais do bezafibrato e da hidroclorotiazida utilizadas para o molecular docking foram obtidas no ZINC12, um banco de dados virtual de estruturas químicas (http://zinc.docking.org).

O docking foi realizado usando as ferramentas do AutoDock Tools (http://autodock.scripps. edu/) acoplado ao software Vina (http://vina.scripps.edu/). As análises de resíduos de aminoácidos envolvidos nas interações droga-proteína e envolvidos no posicionamento do grupo heme após a ancoragem foram feitas usando o software PyMol.

\section{RESULTADOS E DISCUSSÃO}

\section{Análises in vitro}

A espectroscopia de absorção UV-vis permite explorar alterações estruturais em uma proteína e investigar a formação dos complexos proteína-ligante. Assim, a espectroscopia é bastante utilizada por ser uma técnica simples e útil para mensurar modificações estruturais em proteínas (NIENHAUS et al., 2005).

No caso da hemoglobina, os espectros de absorção do grupo heme são muito sensíveis, o que torna a técnica adequada para investigar a interação droga-proteína. A hemoglobina em seu estado ferroso é caracterizada pela banda de Soret, a 405$407 \mathrm{~nm}$ (MESSORI et al., 2006). Os testes in vitro mostraram diminuição da absorção de luz a $405 \mathrm{~nm}$ para os dois fármacos analisados ( $p=0,045$ para bezafibrato e $p=0,022$ para hidroclorotiazida), conforme demonstrado pelas Figuras 1 e 2 .

A variação da absorbância calculada resultou em $\mathrm{k}=8,75 \times 10^{-4} \mathrm{~min}^{-1}$ para o bezafibrato e $\mathrm{k}=6,25 \times 10^{-4}$ $\mathrm{min}^{-1}$ para a hidroclorotiazida. De acordo com esses valores, o bezafibrato parece interagir com uma afinidade ligeiramente maior com a hemoglobina bovina quando comparada à hidroclorotiazida. Segundo Sugihara et al. (1985), a presença de bezafibrato reduz a afinidade do oxigênio dos eritrócitos, pois ele se liga a diferentes sítios de ligação do 2,3-bifosfoglicerato, um regulador alostérico da afinidade da hemoglobina. Segundo esses resultados, podemos inferir que ocorreu uma interação entre os medicamentos testados e a hemoglobina, modificando a estrutura do esqueleto da hemoglobina bovina (HU et al., 2004).

A diminuição no valor de absorbância a $405 \mathrm{~nm}$ indica que houve alteração no posicionamento do grupo heme, possivelmente em virtude da interação da hemoglobina com a droga. Apenas com as análises espectrofotométricas não é possível determinar se a droga se ligou diretamente ao grupo heme ou a algum resíduo de aminoácido próximo, e assim a mudança em seu posicionamento foi transferida ao grupo prostético. Portanto, foram utilizadas técnicas de docagem molecular para avaliar a interação do ligante com a proteína-alvo.

A interação do bezafibrato ou da hidroclorotiazida com a hemoglobina pode interferir tanto na efetividade das drogas, quanto na funcionalidade da 
proteína. Do ponto de vista farmacológico, a ligação das drogas à hemoglobina causa um sequestro destas, diminuindo a fração disponível para ligação ao alvo. As concentrações plasmáticas dessas drogas, necessárias para que elas exerçam seu papel terapêutico no organismo, tornam-se insuficientes, comprometendo o tratamento do paciente (MESSORI et al., 2006).

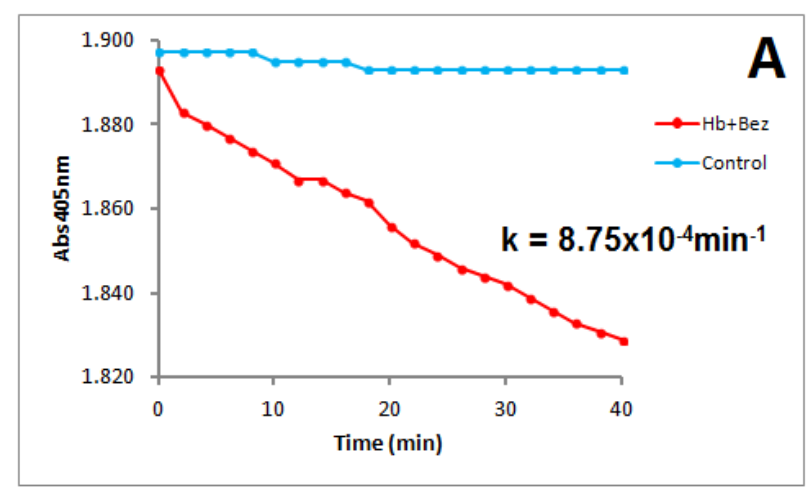

Figura 1: Cinética de reação da interação entre a hemoglobina bovina e bezafibrato.

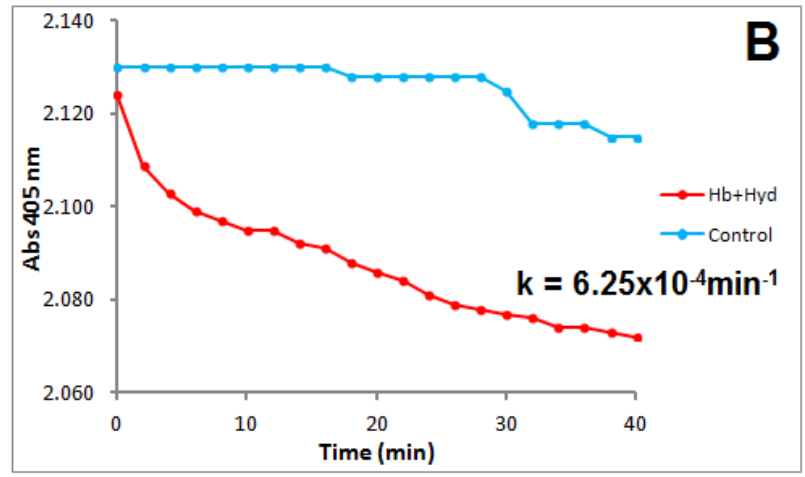

Figura 2: Cinética de reação da interação entre a hemoglobina bovina e hidroclorotiazida.

Características fisiológicas, como taxa de filtração glomerular, concentração de hemoglobina e hematócrito, entre outros, podem variar de indivíduo para indivíduo desencadeando variações também na concentração efetiva da droga. Em relação ao bezafibrato, sua ineficiência terapêutica pode acarretar, em longo prazo, problemas relacionados à alta de triglicérides e de LDL, como patologias cardiovasculares e hipertensão. A ineficácia da ação da hidroclorotiazida pode ter consequências graves em curto espaço de tempo; por se tratar de um diurético utilizado para o controle de hipertensão, o ajuste da pressão arterial sistêmica ficará prejudicada. Logo, ocorrerá uma sobrecarga dos sistemas orgânicos, como o cardiovascular, podendo culminar em acidentes vasculares graves como o acidente vascular encefálico (AVE).

Devido à interação com as drogas, a hemoglobina pode ter sua funcionalidade comprometida, bem como os eventos ligados a ela. As trocas gasosas ficarão comprometidas, logo, a oxigenação dos tecidos será deficiente. Isso será refletido em uma baixa produção energética celular e redução de desempenho fisiológico, culminando em morte celular e dano tecidual.

A ligação da hemoglobina ao bezafibrato induz mudanças estereoquímicas pequenas, mas significativas em torno do grupo heme. Após a ligação do bezafibrato ocorre um encurtamento significativo da distância entre o átomo de ferro do grupo heme e um átomo de nitrogênio do resíduo de histina distal (His E7) da parte proteica da hemoglobina (SHIBAYAMA et al., 2002). Esta alteração no posicionamento do grupo heme possivelmente causa alteração na capacidade de ligação ao oxigênio molecular, a qual foi indiretamente observada pelo decaimento da absorção da banda Soret.

\section{Análises in silico}

\section{Análise de sequência e alinhamento}

A hemoglobina bovina mostra pouca diferença estrutural e funcional em comparação à hemoglobina humana (SAFO et al., 2001). Sendo assim, a hemoglobina bovina e a humana foram analisadas por ferramentas de bioinformática para obter dados de similaridade entre elas.

A análise da composição de aminoácidos mostrou que as cadeias alfa e beta das duas hemoglobinas têm um conteúdo semelhante. As cadeias alfa têm o mesmo número de resíduos (141) e na cadeia beta da hemoglobina humana há um resíduo a mais (146) do que a hemoglobina bovina (145).

$O$ alinhamento das sequências primárias das hemoglobinas mostrou que a posição dos aminoácidos é conservada (Figuras 3 e 4). As cadeias alfa mostraram $92,2 \%$ de similaridade de sequência e as cadeias beta apresentaram $90,4 \%$. 
Nas cadeias alfa, 17 resíduos são diferentes. Entre estes 17 resíduos, 12 foram substituídos por outros resíduos com cadeia lateral semelhante (em carga ou em tamanho). Os cinco restantes têm cadeias laterais completamente diferentes em tamanho ou carga. Na posição oito da sequência primária das cadeias alfa pode ser observada uma substituição Gly/Thr (2QSS/2H35); uma substituição Ala/Lys (2QSS/2H35) na posição 60, Ala/Asp (2QSS/2H35) na posição 64, Glu/Ala (2QSS/2H35) nas posições 71 e 82 . Em suma, houve substituição de resíduos de aminoácidos não carregados por carregados ou hidrofóbicos por hidrofílicos.

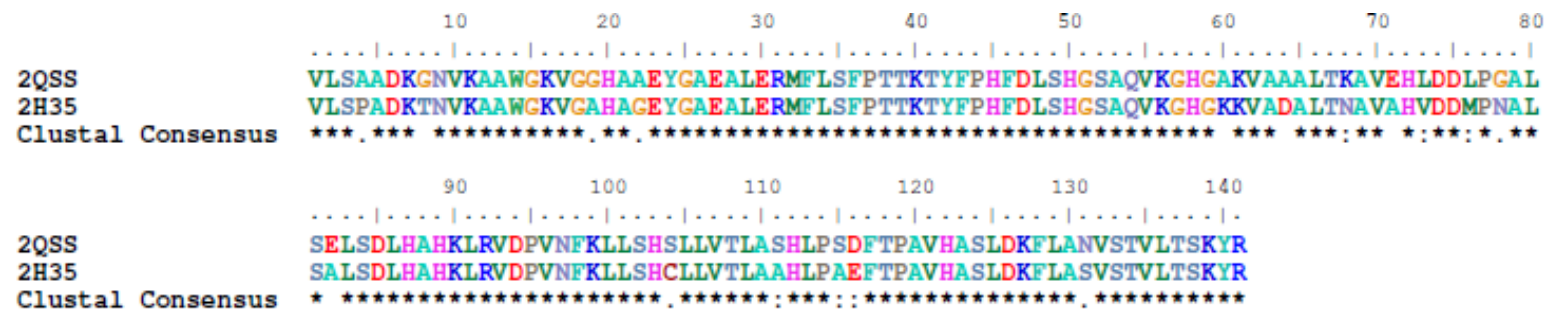

Figura 3: Alinhamento das cadeias alfa. 2QSS (Hb bovina), $2 \mathrm{H} 35$ ( $\mathrm{Hb}$ humana). Um e dois pontos mostram as substituições semelhantes; Substituições não semelhantes não são marcadas. ${ }^{*}=$ Sem substituições.

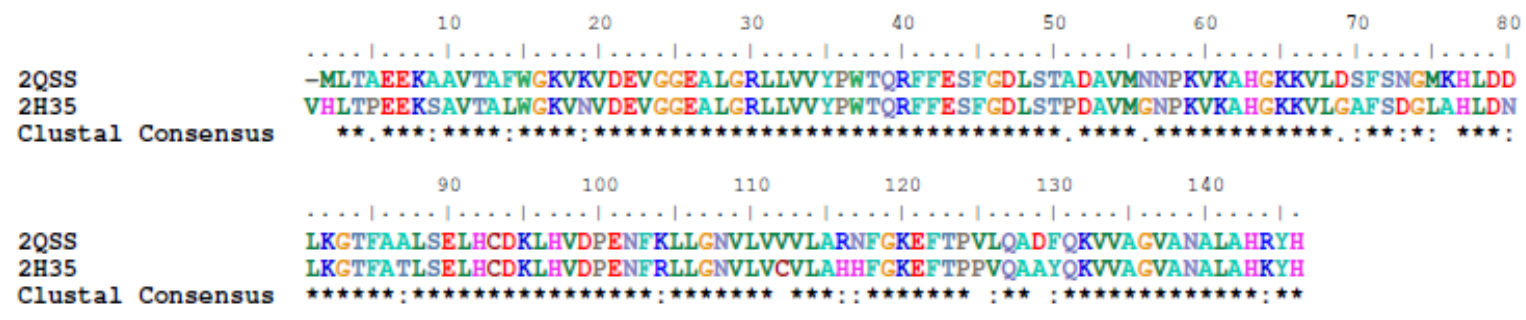

Figura 4: Alinhamento das cadeias beta. 2QSS (Hb bovina), 2H35 (Hb humana). Um e dois pontos mostram as substituições semelhantes; Substituições não semelhantes não são marcadas. ${ }^{*}=$ Sem substituições.

Nas cadeias betas há 24 resíduos diferentes, dos quais 18 são substituições semelhantes (em carga e tamanho). Não ocorre alinhamento no primeiro aminoácido, pois ocorre um gap na hemoglobina bovina ao parear com a Val 1 da hemoglobina humana, então o primeiro aminoácido da hemoglobina bovina se alinha ao segundo da hemoglobina humana e assim por diante. As demais substituições são Met1/His2 (2QSS/2H35), Lys75/ Ala76 (2QSS/2H35), Val111/Cys112 (2QSS/2H35),
Val124/Pro125 (2QSS/2H35) e Asp128/Ala129 (2QSS/2H35).

Essas mudanças são significativas e podem conferir diferentes pontos isoelétricos para as hemoglobinas e causar mudanças na estrutura tridimensional. No entanto, a análise do posicionamento dos resíduos alterados na estrutura tridimensional mostrou que eles não estão próximos do grupo heme, assim tais resíduos não interferem significativamente na posição deste grupo (Figuras 5 e 6 ). 


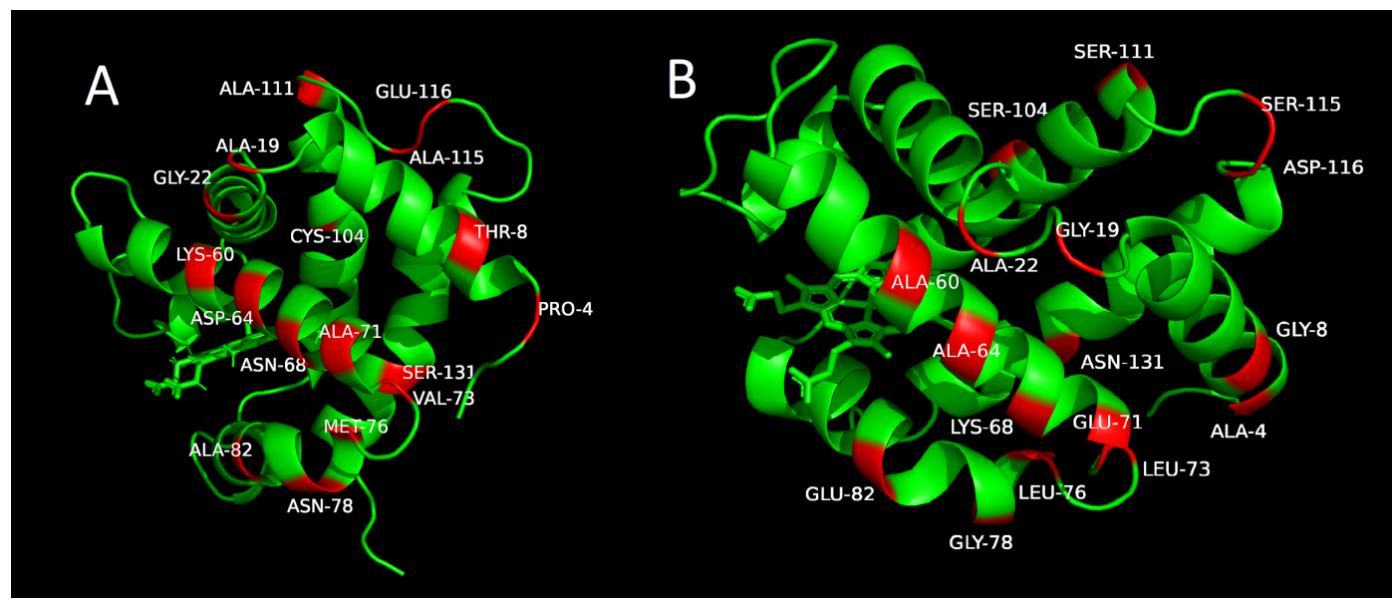

Figura 5: Posição das substituições dos resíduos de aminoácidos mais significativas na cadeia alfa da hemoglobina humana (A) e bovina (B). Resíduos de aminoácidos diferentes estão em evidência; seu nome e sua posição na sequência primária são mostrados.

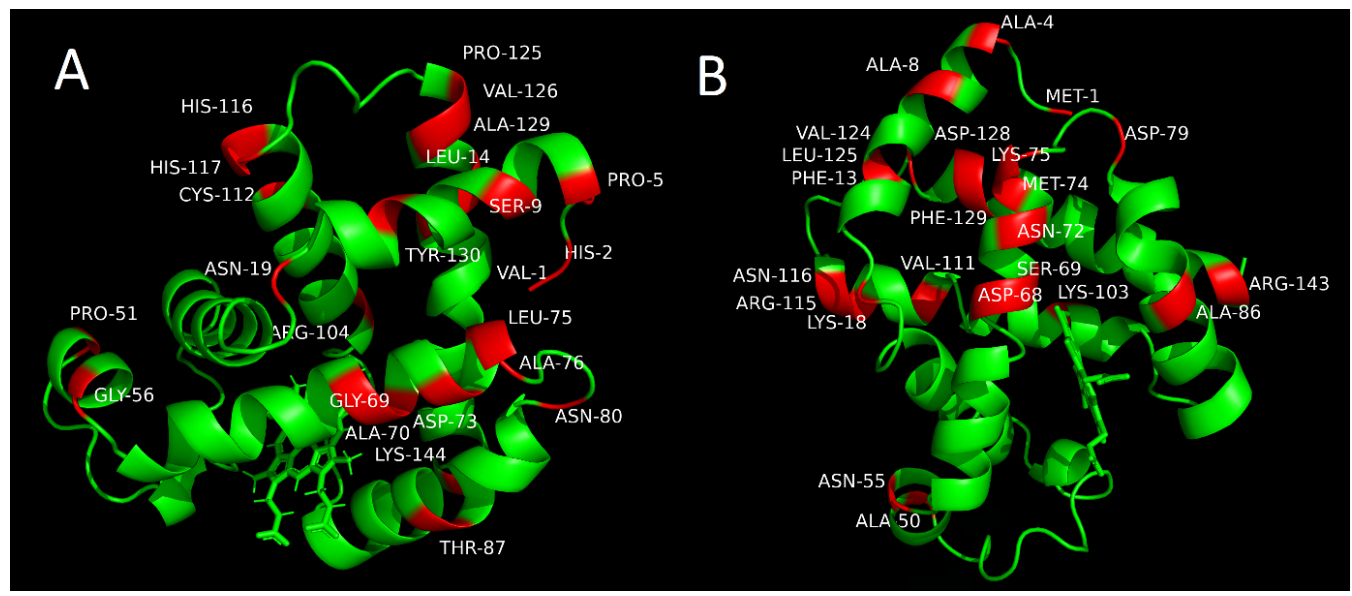

Figura 6: Posição das substituições dos resíduos de aminoácidos mais significativas na cadeia beta da hemoglobina humana (A) e bovina (B). Resíduos de aminoácidos diferentes estão em evidência; seu nome e sua posição na sequência primária são mostrados.

\section{Docagem Molecular (molecular docking)}

A docagem molecular foi utilizada para analisar, em nível molecular, o local de interação dos fármacos hidroclorotiazida e bezafibrato com as hemoglobinas humana (2H35) e bovina (2QSS). A simulação se faz necessária para entender melhor a dinâmica da interação entre proteína-ligante (MENG et al., 1992).

Nas docagens realizadas com a hemoglobina humana foi demonstrado que o bezafibrato e a hidroclorotiazida não interagem diretamente com o grupo heme, e sim com a parte proteica da hemoglobina.

O bezafibrato apresentou interações polares com comprimento de $2,4 \AA$ com o resíduo Thr38 da cadeia a1 (cadeia A), 2,4 $\AA$ com o resíduo Lys 132 da cadeia $\beta 1$ (cadeia B) e $2,1 \AA$ com a His97 da cadeia $\beta 2$ (cadeia D) (Figura 7). A hidroclorotiazida fez interações de $2,1 \AA$ com o resíduo Thr38 da cadeia a2 (cadeia C) e 2,3 $\AA$ com a Arg104 da cadeia $\beta 2$ (cadeia D) (Figura 8 ).

A afinidade de interação, calculada em kcal/ mol pelo AutoDock Vina, foi de $-7,6 \mathrm{kcal} / \mathrm{mol}$ para o complexo formado pela hemoglobina humana com bezafibrato e $-6,7 \mathrm{kcal} / \mathrm{mol}$ para a hemoglobina humana com hidroclorotiazida.

Enquanto o bezafibrato manteve duas interações polares de $2,1 \AA$ e $2,5 \AA$ com o aminoácido Arg39 da cadeia $\beta 1$ (cadeia B), uma de $3,5 \AA$ com o 
aminoácido Tyr42 e outra de 2,2 § com o aminoácido Arg92 da cadeia a2 (cadeia C) (Figura 9), a hidroclorotiazida manteve uma interação polar de $3,4 \AA$ com o resíduo Ser138 da cadeia a1 (cadeia A), uma interação de 3,4 $\AA$ com o Asp126 e outra interação de 3,5 $\AA$ com a Asn131, ambos da cadeia a2 (cadeia C).

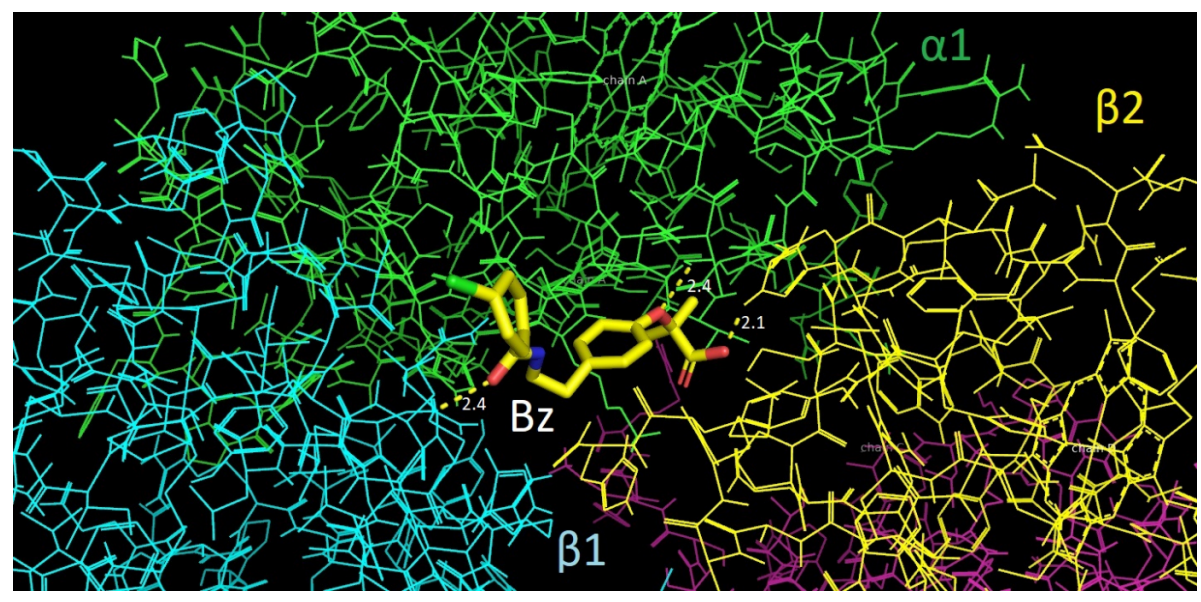

Figura 7: Interações polares do bezafibrato (sticks) com a hemoglobina humana (lines), representadas por linhas tracejadas amarelas, com os resíduos Thr38 ( $\alpha 1)$, Lys132 ( $\beta 1)$ e His97 ( $\beta 2)$ da hemoglobina humana. Bz: bezafibrato.

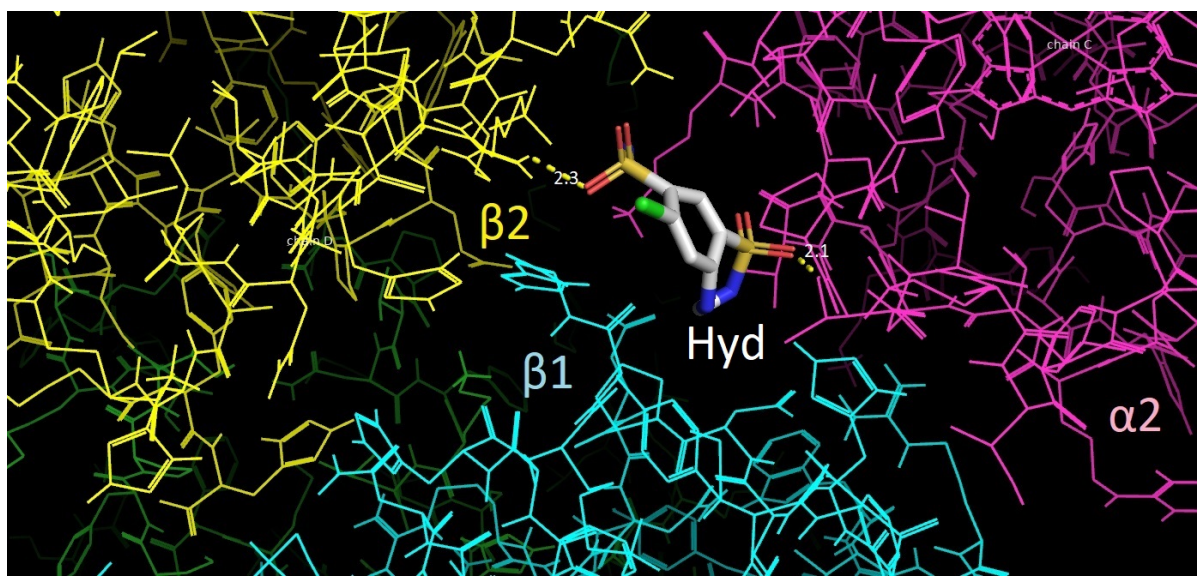

Figura 8: Interações polares da hidroclorotiazida (sticks) com a hemoglobina humana (lines), representadas por linhas tracejadas amarelas, com os aminoácidos Thr38 ( $\alpha 2)$ e Arg104 ( $\beta 2)$ da hemoglobina humana. Hyd: hidroclorotiazida.

A afinidade da ligação foi de $-8,3 \mathrm{kcal} / \mathrm{mol}$ para o complexo formado entre hemoglobina bovina e bezafibrato, e $-6,6 \mathrm{kcal} / \mathrm{mol}$ para hemoglobina bovina e hidroclorotiazida. $\mathrm{O}$ fato de o bezafibrato realizar quatro ligações polares com hemoglobina bovina (Figura 9 ) indica o motivo da maior afinidade de interação (mostrado pelo valor de k e pela afinidade em $\mathrm{kcal} / \mathrm{mol}$ ) quando comparada à da hidroclorotiazida. O mesmo é observado para os complexos formados com bezafibrato e hidroclorotiazida ligados à hemoglobina humana, uma vez que apresentam três e duas interações polares, respectivamente.
O fato de o bezafibrato interagir mais fortemente com a hemoglobina, quando comparado à hidroclorotiazida, sugere que a ação desta última seria mais afetada. Tal fato possibilita também extrapolar uma hipótese de interação medicamentosa. Ao serem administradas de forma conjunta, por afinidade o bezafibrato consegue se ligar à hemoglobina em detrimento da hidroclorotiazida. Logo, a funcionalidade terapêutica do bezafibrato será comprometida, enquanto a da hidroclorotiazida terá melhor desempenho. 


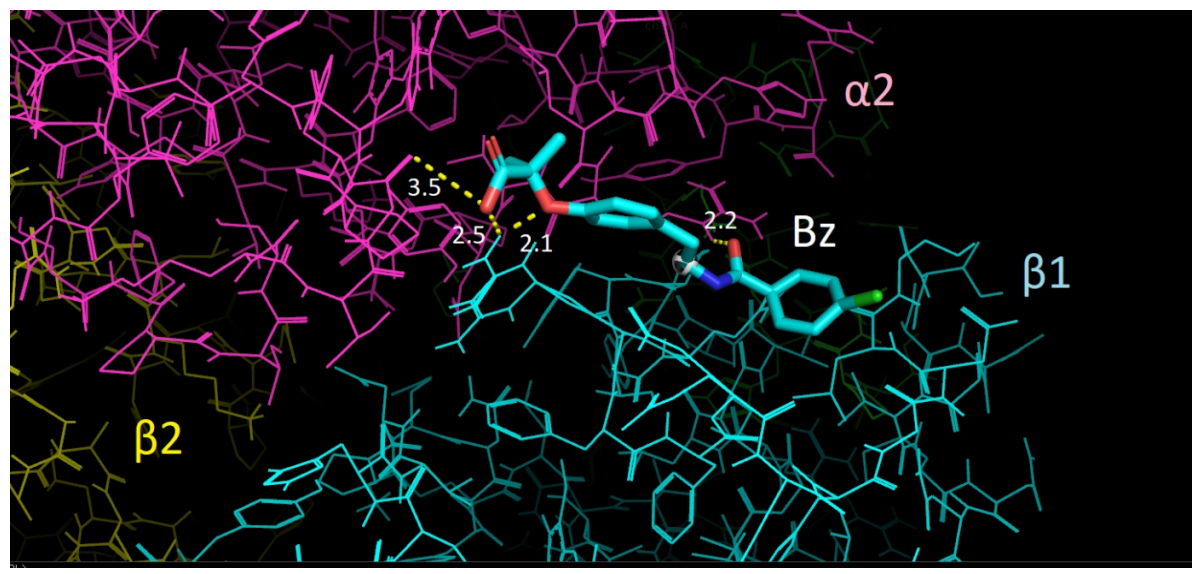

Figura 9: Interações polares do bezafibrato (sticks) com a hemoglobina bovina (lines), representadas por linhas tracejadas amarelas, com os aminoácidos Arg39( $\beta 1)$, Tyr42 ( $\alpha 2)$ e Arg92 ( $\alpha 2)$ da hemoglobina bovina. Bz: bezafibrato.

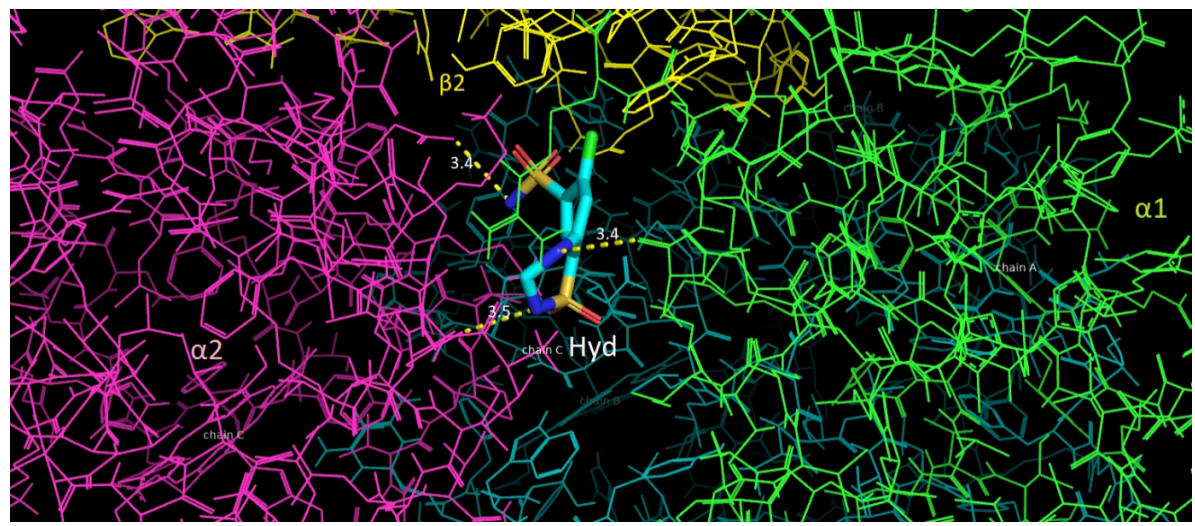

Figura 10: Interações polares da hidroclorotiazida (sticks) com a hemoglobina bovina (lines), representadas por linhas tracejadas amarelas, com os aminoácidos Ser138 (a1), Asp126 (a2) e Asn131 (a2) da hemoglobina bovina. Hyd: hidroclorotiazida.

\section{RMSD}

Em bioinformática, o desvio da raiz quadrada média (RMSD) de posições atômicas é útil na validação da docagem molecular e representa a medida da distância média entre os átomos de proteínas sobrepostas; O RMSD é calculado em relação ao melhor confórmero obtido na docagem e usam apenas átomos pesados móveis. Como resultado da docagem, obtemos duas variantes métricas de RMSD: rmsd/lb (limite inferior do RMSD) e rmsd/ub (limite superior RMSD), as quais diferem pela forma como os átomos são correspondidos no cálculo da distância. Enquanto no rmsd/ ub cada átomo é combinado em uma conformação com ele próprio na outra conformação, ignorando qualquer simetria, no rmsd/lb cada átomo é combinado em uma conformação com o mais próximo átomo do mesmo tipo de elemento na outra conformação (TROTT et al., 2010), sendo que no presente as docagens realizadas apresentaram o valor zero para ambas as métricas.

\section{CONCLUSÃO}

No presente estudo, as técnicas de espectroscopia e ancoragem molecular foram utilizadas para elucidar a natureza das interações entre os fármacos bezafibrato e hidroclorotiazida com a hemoglobina bovina e humana. Verificou-se por meio do decréscimo na absorbância na banda Soret que estas drogas interagem com a hemoglobina bovina in vitro, e devido à similaridade de sequência entre ambas as proteínas, possivelmente essa interação deve ocorrer com a hemoglobina humana. As análises de ancoragem molecular mostraram que possivelmente a hemoglobina é capaz de se ligar a essas drogas terapêuticas no organismo vivo, por meio de sua parte proteica. Os resultados sugerem que o bezafibrato se liga mais fortemente à hemoglobina humana e bovina, quando comparado 
à hidroclorotiazida. Os resultados in silico corroboram os resultados in vitro, e a inferência de maior afinidade do bezafibrato pode ser explicada pelo maior número de interações químicas observadas em relação à hidroclorotiazida. Sugere-se, portanto que a função normal da hemoglobina pode ser modificada uma vez que a interação com os fármacos pode mudar sua conformação; isso pode alterar o microambiente do bolsão do heme, afetando, assim, o estado de oxidação do átomo central de ferro, interferindo na interação com o oxigênio molecular. Além disso, ao se ligar à hemoglobina a fração livre do fármaco é alterada, e consequentemente sua posologia e eficiência terapêutica. Considerando-se os fármacos analisados é possível sugerir que a ação do bezafibrato seria mais afetada em relação à hidroclorotiazida; entretanto, isoladamente ambas teriam alteração de funcionalidade que seriam observadas clinicamente como dificuldades no controle do perfil lipoproteico e no controle da hipertensão, respectivamente.

\section{REFERÊNCIAS}

1. BRUNTON, LAURECEN.L. Diuréticos e Outras Substâncias Empregadas na Mobilização do Líquido de Edema. In Gilman, A.; Goodman, L. \& Gilman, A. (13 ed): As Bases Farmacológicas da Terapêutica, Artmed, 2019.

2. CHAKRABORTI, A.S. Interaction of porphyrins with heme proteins-a brief review. Mol. Cell Biochem. v. 253, n. 1, p. 49-54, 2003.

3. CHEEMA, M.A.; TABOADA, P.; BARBOSA, S.; CASTRO, E.; SIDDIQ, M.; MOSQUERA, V. Modification of the thermal unfolding pathways of myoglobin upon drug interaction in different aqueous media. J. Phys. Chem. B. v. 111, n. 49, p.13851-13857, 2007.

4. COSTA, M. D. S.; KIRALJ, R.; FERREIRA, M. M. C. Estudo teórico da interação existente entre a artemisinina e o heme. Quimica Nova, v. 30, p. 25-31, 2007.

5. DUMAN, O.; TUNÇ, S.; KANCI BOZOĞLAN, B. Characterization of the binding of metoprolol tartrate and guaifenesin drugs to human serum albumin and human hemoglobin proteins by fluorescence and circular dichroism spectroscopy. Journal of Fluorescence, v. 23, n. 4, p. 659-669, 2013.

6. GOA, K.L.; BARRADELL, L.B.; PLOSKER, G.L. Bezafibrate. An update of its pharmacology and use in the management of dyslipidaemia. Drugs, 53(1):188, 1997.

7. HAGE, D.S; JACKSON, A.; SOBANSKY, M.; SCHIEL, J.E.; YOO, M.J.; JOSEPH, K.S. Characterization of drug-protein interactions in blood using high-performance affinity chromatography. Sep. Sci. v. 32, n. 5-6, p. 835-853, 2009.
8. HOBANI, Y.; JERAH, A.; BIDWAI, A. A comparative molecular docking study of curcumin and methotrexate to dihydrofolate reductase. Bioinformation v. 13 n. 3, p. 63-66, 2017.

9. HU, Y.J.; WANG, J.B.; XIAO, X.H.; QU, S.S. Study of the interaction between monoammonium glycyrrhizinate and bovine serum albumin. J Pharm Biomed Anal, v. 36, n. 4, p. 915-919, 2004.

10. IRWIN, J.J; STERLING, T.; MYSINGER, M.M.; BOLSTAD, E.S.; COLEMAN, R.G. ZINC: A free tool to discover chemistry for biology. J. Chem. Inf. Model. v. 52, n. 7, p. 1757-1768, 2012.

11. KAMALJEET.; BANSAL, S; UTTARA, S. A study of the interaction of bovine hemoglobin with synthetic dyes using spectroscopic techniques and molecular docking. Frontiers in chemistry, v. 4, p. 50, 2017.

12. KRATOCHOWIL, N.A.; HUBER, W.; MULLER, F.; KANSY, M.; GERBER, P.R. Predicting plasma protein binding of drugs: a new approach. Biochem. Pharmacol. v. 64, p. 1355-1374, 2002.

13. KWONG, T.C. Free drug measurements: methodology and clinical significance. Clin. Chim. Acta v. 151, n. 3, p. 193-216, 1985.

14. LALEZARI, I.; LALEZARI, P.; POYART, C.; MARDEN M. ; KISTER J.; BOHN B.; FERMI G.; PERUTZ M.F. NeW effectors of human hemoglobin: structure and function. Biochemistry 29(6): 1515-1523, 1990.

15. LI, Y.; WEI, H.; LIU, R. A probe to study the toxic interaction of tartrazine with bovine hemoglobin at the molecular level. Luminescence. v. 29, n. 2, p. 195-200.

16. LIU, Y.; LIU, R. Spectroscope and molecular model identify the behavior of doxorubicin-SPION binding to bovine hemoglobin. Int.J.Biol.Macromol. v. 79, p. 564-569, 2015.

17. MALTAS, E.; OZMEN, M. Spectrofluorometric and thermal gravimetric study on binding interaction of thiabendazole with hemoglobin on epoxy-functionalized magnetic nanoparticles. Mater Sci Eng C Mater Biol Appl. v. 54, p. 43-49, 2015.

18. MARTIN, A.; SWARBRICK, J.; CAMMARATA, A.: In: Physical Pharmacy, 3 ed. Virghese Publishing House, India, p 314-351, 1991.

19. MENG, E. C., SHOICHET, B. K.; KUNTZ, I. D. Automated docking with grid-based energy evaluation. J. Comput. Chem. v. 13, p. 505-524, 1992.

20. MESSORI, L.; GABBIANI, C.; CASINI, A.; SIRAGUSA, M.; VINCIERI, F.F.; BILIA, A.R. The reaction of artemisinins with hemoglobin: a unified picture. Bioorgan. Med. Chem. v. 14, n. 9, p. 2972-2977, 2006.

21. NIENHAUS, K.; NIENHAUS, G.U. Probing heme protein-ligand interactions by UV/visible absorption spectroscopy. In: Protein-Ligand Interactions. Humana Press. v. 305, p. 215-241, 2005.

22. SAFO, M. K.; ABRAHAM, D. J. The X-ray structure determination of bovine carbonmonoxy hemoglobin at $2.1 \AA$ resoultion and its relationship to the quaternary 
structures of other hemoglobin crystal forms. Protein Sci. v. 10, n. 6, p. 1091-1099, 2001.

23. SHIBAYAMA, N.; MIURA, S.; TAME, J.R.H.; YONETANI, T.; PARK, S.Y. Crystal structure of horse carbonmonoxyhemoglobin-bezafibrate complex at $1.55-\mathrm{A}$ resolution. A novel allosteric binding site in R-state hemoglobin. J Biol Chem, 277(41):38791-38796, 2002.

24. SUGIHARA, J.; IMAMURA, T.; NAGAFUCHI, S. BONAVENTURA, J.; BONAVENTURA, C.; CASHON, R. Hemoglobin Rahere, a human hemoglobin variant with amino acid substitution at the 2, 3-diphosphoglycerate binding site. Functional consequences of the alteration and effects of bezafibrate on the oxygen bindings. The Journal of clinical investigation, v. 76, n. 3, p. 11691173, 1985.

25. THE EUROPEAN BIOINFORMATICS INSTITUTE (EMBLEBI) (org). Pairwise Sequence Alignment. Disponível em: https://bit.ly/2zm6l4a. Acesso em 08/05/2020

26. THOMPSON, J.D.; HIGGINS, D.G; GIBSON, T.J. CLUSTAL $\mathrm{W}$ : improving the sensitivity of progressive multiple sequence alignment through sequence weighting, position-specific gap penalties and weight matrix choice. Nucleic Acids Res. v. 22, n. 22, p. 4673-4680, 1994.
27. TONG, Z.; SCHIELA, J.E.; PAPASTAVROSA, E.; OHNMACHTA, C.M.; SMITH, Q.R.; HAGE, D.S. Kinetic studies of drug-protein interactions by using peak profiling and high-performance affinity chromatography: examination of multi-site interactions of drugs with human serum albumin columns. J. Chromatogr. A. v.1218, n.15, p. 2065-2071, 2011.

28. TROTT, O.; OLSON, A.J. AutoDock Vina: improving the speed and accuracy of docking with a new scoring function, efficient optimization and multithreading. Journal of Computational Chemistry, v. 31, 2010, p. 455-461.

29. WANG, Y.; ZHANG, H., ZHOU, Q.; XU, H. A study of the binding of colloidal $\mathrm{Fe} 3 \mathrm{O} 4$ with bovine hemoglobin using optical spectroscopy. Colloids and Surfaces A: Physicochemical and Engineering Aspects, v. 337, n. 1-3, p. 102-108, 2009.

30. WEST, J.B.: In: Best and Taylor's Physiological Basis of Medical Practices, 11 ed. Williams and Wilkins, London, 1985, p. 546-571.

31. WU, J.; LORUSSO, P.M.; MATHERL, L.H.; LI, J. Implications of Plasma Protein Binding for Pharmacokinetics and Pharmacodynamics of the $Y$-Secretase Inhibitor RO4929097. Clin. Cancer Res. v.18 n.7, 2012.

\section{Declaração de Conflito de Interesses}

Não há conflito de interesses entre os autores deste estudo.

\section{Contribuições dos Autores}

Bianca Luiza Melo de Assis - Responsável pelas análises e escolha dos modelos de bioinformática, pelas análises espectrofotométricas in vitro e pela escrita do manuscrito - 25\%; Anderson Dillmann Groto - Responsável pelas análises de molecular docking, análises estatísticas e pela escrita do manuscrito - 22\%; Vítor Hugo Mota - Responsável pelas análises de molecular docking e pela escrita do manuscrito - 20\%; Gabriele Caroline Peiter - Responsável pela análise crítica do manuscrito, escrita e correção do manuscrito - 20\%; Kádima Nayara Teixeira - Autora da ideia da pesquisa. Supervisão de todas as etapas do estudo. Tradução do artigo para a língua inglesa - 13\%

Autor correspondente:

Bianca Luiza Melo de Assis

biancaluiza@ufpr.br

Editor:

Prof. Dr Felipe Villela Gomes

Recebido em: 07/07/2020

Aprovado em: 26/08/2020 